\title{
KELAYAKAN PEGAS DAUN DALAM PENERIMAAN BEBAN OPTIMAL
}

\author{
DARYONO \\ Jurusan Teknik Mesin Universitas Muhammadiyah Malang \\ E-mail: daryono_umm@yahoo.com
}

\begin{abstract}
ABSTRAK
Sampai saat ini banyak kendaraan darat yang menggunakan suspensi model pegas daun. Jenis suspensi ini terdiri dari beberapa susunan lempeng. Penelitian ini difokuskan sebatas test laboratorium saja dan tidak menggunakan pengujian lapangan atau ekperimen karenanya hasil atau kesimpulan yang diperoleh bersifat teoritis. Besarnya harga frekuensi natural dari semua mode getaran berdasarkan hasil modal analisis diperoleh harga diatas $100 \mathrm{~Hz}$ yang melampaui batas aman baik dari segi kemanan desain konstruksi suspensi itu sendiri maupun bagi keamanan penumpangnya. Tetapi dengan menggunakan simulasi harmonik dengan input frekuensi sebesar $1 \mathrm{~Hz}$ samapi dengan $10 \mathrm{~Hz}$ dihasilkan besarnya simpangan atau ampltudo getar tidak lebih dari $20 \mathrm{~mm}$ yang masih masuk batas aman untuk kenyamanan penumpang atau manusia berdasarkan diagram kenyamanan menurut Jane Way. Hal inilah yang menyebabkan masih terpakainya suspensi jenis pegas daun untuk kendaraan darat oleh masyarakat pengguna otomotif.
\end{abstract}

Kata kunci: pegas daun, suspensi, keamanan, kenyamanan

\begin{abstract}
Nowdays a lot of vehicle still used suspension Leaf spring either in front or in rear suspension. Commonly, his suspension consist of several peace of springs that called leaf spring. This research is focus on laboratory work without experimental test. As a result only theoretical conclusion. Natural frequency by modal analysis show that all mode are more than $100 \mathrm{~Hz}$. It is very dangerous value of safety passengers and the suspension its self. But with harmonik simulation between 1 until $10 \mathrm{~Hz}$ input frequency will be resulted no more than $20 \mathrm{~mm}$ amplitude. This is the range where passenger still get comfortability according to Jane way diagram of comfort ability. Consequently a lot of people or automotive engineer still use this kind of suspension.
\end{abstract}

Key words: leaf spring, suspension, safety, comfort

\section{PENDAHULUAN}

Penggunaan pegas daun sebagai suspensi kendaraan untuk transfortasi darat masih relevan eksistensinya yang mana hampir $85 \%$ suspensi untuk kendaraan truck menggunakan model suspensi pegas daun (Fu, 2002). Jika dilihat dari konstruksi dan kondisi pemasangan suspensi pegas daun ini menunjukan adanya suatu keunikan yaitu pada susunan pegas yang melengkung dengan radius kelengkungan tertentu sampai lapisan yang paling akhir (Norman, 2002). Demikian pula jika ditinjau dari segi jumlah pemakain yang begitu relevan jumlahnya menunjukan bahwa memang ada suatu keistimewahan yang tersembunyi pada konstruksi pegas daun atau "Leaf Spring" sebagai suspensi kendaraan darat ini. Namun belum ada suatu desain yang paling bagus mengenai berapa jumlah susunan lempeng pegas yang akan memberikan kualitas kenyamanan maupun keamanan yang paling baik (Shankar, 2006).

Beberapa peneitian yang berkaitan dengan hal ini antara lain optimasi gelagar tumpuan sederhana dengan menggunakan ANSYS' 5.4 mengungkapkan bahwa hasil optimasi menunjukan bahwa dengan model lengkung dari geometri awal beberbentuk segi empat memberikan kekuatan yang sama dengan contour penuh. (Wijayanto dan Daryono, 2002). Dilanjutkan dengan studi karakteristik variasi gelagar dengan profil segi empat" menyatakan bahwa dengan radius kelengkungan tertentu ternya memberikan kekuatan gelagar yang lebih tinggi dibanding model gelagar tanpa kelengkungan atau gelagar lurus untuk profil dan volume material yang sama (Miftahurrozi dan Daryono, 2005). Demikian juga penelitian tentang Studi Penggunaan Pegas daun sebagai suspensi mobil Kijang menyimpulkan 
bahwa dengan model susunan seperti pada susunan kendaraan roda empat lainnya diperoleh harga tegangan maksimum yang terjadi masih di bawah batas harga kekuatan ijin bahan (Tomy dan Daryono, 2005).

Pada kesempatan ini akan dikaji karakteristik pegas daun akibat pembebanan dinamis dengan tujuan untuk mempelajari karakteristik dinamik yang berupa besar frekuensi dan amplitudo getaran pada kendaraan roda empat sehingga menghasilkan kenyamanan yang bisa diterima oleh manusia/ penumpang sesuai dengan kekuatan atau batas keamanan bahan pegas yang dimodelkan.

\section{METODE}

Pegas daun yang umumnya digunakan pada mobil adalah bentuk semi-elliptikal seperti ditunjukkan pada Gambar 1. Pegas daun ini terbentuk dari sejumlah pelat-pelat (berbentuk seperti daun). Daundaun ini biasanya mempunyai ciri dilengkungkan sehingga daun-daun itu akan melayani untuk melentur menjadi lurus oleh karena kerja beban.

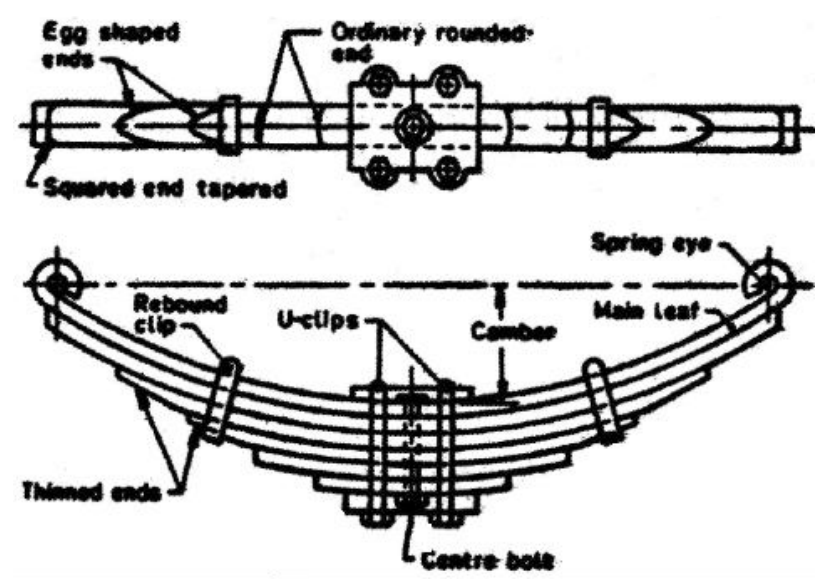

Gambar 1. Pegas Daun Semieliptikal

Daun-daun itu disatukan bersama oleh sabuk seperti gelang yang disusutkan melingkarinya pada posisi tengah atau dengan baut yang menembusnya di tengah. Sabuk tersebut menggunakan efek kuat dan kokoh, oleh karena itu panjang efektif pegas untuk melentur akan menjadi panjang keseluruhan pada pegas dikurangi lebar dari sabuk. Dalam hal sabuk tengah (centre bolt), dua per tiga jarak di antara pertengahan sabuk-U (U-bolt) akan dikurangi dari panjang keseluruhan pegas agar mendapatkan panjang efektif. Pegas ditumpukkan pada rumah poros dengan menggunakan sabuk-U.

Daun yang lebih panjang dikenal sebagai daun utama (main leaf atau master leaf) dengan ujung dibentuk menyerupai lubang mata yang mana di pasang dengan baut untuk mengikat pegas pada tumpuannya. Biasanya pada mata tersebut, pegas disematkan pada sengkang (shackle), yang juga diberikan bantalan yang terbuat dari bahan anti gesekan seperti perunggu (bronze) atau karet (rubber). Daun pegas yang lainnya dikenal sebagai graduated leaves. Agar mencegah terjadinya gesekan atau desakan pada daun yang berbatasan, ujungujung dari graduated leaves diatur dalam bermacammacam bentuk seperti diperlihatkan oleh gambar 1 .

Daun utama akan melawan beban-beban lentur vertikal dan juga beban-beban yang disebabkan bagian samping kendaraan dan torsi, oleh karena adanya tegangan disebabkan oleh beban-beban ini, sudah menjadi kebiasaan memberikan dua daun dengan panjang penuh dan blok bantalan pada daun tersusun (graduated leaves) seperti ditunjukkan pada gambar 1. Jepitan pantul (rebound clips) diletakkan pada posisi pertengahan panjang pegas, sehingga susunan daun-daun juga ikut andil menghantarkan tegangan pada daun panjang penuh (full length leaves) ketika pegas memantul.

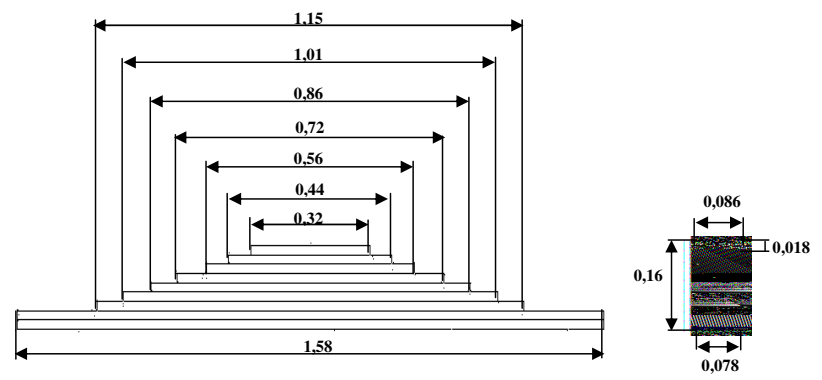

Gambar 2. Dimensi Pegas Daun (Leaf Spring)

Data-data spesifikasi Dumptruck sebagai berikut:

Merk Kendaraan: Nissan Type: CWB 520 HDN, Berat bersih Dumptruck: $12.600 \mathrm{~kg}$

Berat muatan Dumptruck: 17.400 kg, Panjang Chasis: 7,025 m, Lebar Chasis 1,256 m

Panjang Dump: 5 m,. Dimensi panjang pegas daun Dumptruck:

Pegas No. 1: 1,58 m,

Pegas No. 2: $1,58 \mathrm{~m}$,

Pegas No. 3: $1,15 \mathrm{~m}$

Pegas No. 4: 1,01 m,

Pegas No. 5: 0,86 m,

Pegas No. 6: 0,72 m

Pegas No. 7: 0,56 m,

Pegas No. 8: 0,44 m,

Pegas No. 9: 0,32 m

Lebar Pegas Daun Dumptruck: 0,086 m,

Tebal Pegas Daun Dumptruck: 0,018 m

Bahan Pegas: Baja DIN 17222, 
Modulus eleastisitas (E): $20,6.10^{10} \mathrm{~N} / \mathrm{m}^{2}$

Tegangan ijin $\left(\sigma_{\mathrm{B}}\right): 67.10^{9}-2,16.10^{9} \mathrm{~N} / \mathrm{m}^{2}$,

Density $(\rho): 7850 \mathrm{Kg} / \mathrm{m}^{3}$

Angka poisson (v): 0,34

Adapun langkah-langkah yang dilakukan dalam metode penelitian ini mendapatkan data spesifikasi pegas dan kendaraan dari survei lapangan, maka dilakukan perhitungan beban maksimum yang harus diterima oleh pegas kemudian dilakukan pembuatan model dengan program ANSYS 6.0. Dalam pemodelan ini model yang dibuat berupa benda solid (3D). Dalam hal ini komponen-komponen suspensi belakang tidak digabungkan ( $a d d$ ) melainkan hanya disambung (Glue) sehingga walaupun satu kesatuan (solid) tetapi masih dapat dipisah-pisah dengan memberikan nama pada tiap-tiap bagian yang telah dibuat tanpa memengarui hasil dari analisis.

Selanjutnya dilakukan uji modal analisis untuk mengetahui besar frekuensi naturan yang terjadi pada model kemudian selanjutnya dilakukan uji harmonik analisis untuk mendapatkan besar distribusi tegangan dan distribusi defleksi pada masing-masing mode getaran yang terjadi. Selanjutnya akan dicari hubungan besar defleksi dan frekuensi natural yang terjadi untuk mendapatkan kualitas kenyamanan menurut standart Jane way sedangkan besar tegangan maksimum dikoreksi dengan kekuatan ijin bahan pegas yang disediakan

\section{HASIL DAN PEMBAHASAN}

Analisis dilakukan menggunakan Software Ansys 6.0. Perbandingan hasil analisis pegas daun suspensi belakang dumptruck disajikan di Tabel 1 .

Analisa hasil simulasi ANSYS 6.0 dengan modal analisis diperoleh untuk kondisi pegas daun yang dimodelkan diperoleh 5 modus getar dengan besar frekuensi maksimum yang ditimbulkan oleh kontruksi pegas rata-rata diatas $100 \mathrm{~Hz}$. Jika kondisi ini betul-betul terjadi saat mobil berjalan maka tegangan maksimum yang akan terjadi pada lempengan pegas nomor empat diatas yaitu sebesar setara dengan $71,6 \mathrm{~N} / \mathrm{mm}^{2}$. Sedangkan besarnya lendutan maksimum yang terjadi adalah sebesar 0,067 $\mathrm{m}$ atau sama dengan $67 \mathrm{~mm}$, maka material yang tidak aman karena jauh melebihi kekuatan ijinya juga akan memberikan efek yang sangat tidak nyaman bagi penumpangnya berdasarkan standart Jane way.

Kenyataannya eksitasi sistem suspensi untuk kendaraan roda empat ini salah satunya berupa profil jalan yang dalam penelitian kali ini dimodelkan sebagai fungsi sinusoidal akibat suatu tanjakan atau karena mobil harus melewati suatu celah jalan yang rusak dengan lebar celah tertentu. Sehingga dalam simulasi berikutnya atau pada langkah berikutnya mensimulasikan sistem suspensi pegas daun ini dalam kondisi gerakan harmonik dengan input frekuensi mulai sebesar $1 \mathrm{~Hz}$ sampai harga frekuensi maksimum akibat perubahan laju kecepatan kendaraan saat mau melewati profil jalan yang identik dengan fungsi sinusoidal tersebut. Dalam penelitian ini kami mengasumsikan bahwa kendaraan akan melewati profil sinusoidal ini tiap jarak lintasan $1 \mathrm{~km}$ sehingga jika kendaraan atau mobil benar-benar melaju dengan kecepatan 100 Km/ jam, maka untuk menempuh jarak lintasan sepanjang $10 \mathrm{~km}$ akan terjadi pengulangan eksitasi sebanyak 10 kali dan besarnya frekuensi eksitasi sebagi input untuk gerak harmonik ini menjadi: 10/(10/100) kali/ jam atau setara $1,65 \mathrm{~Hz}$.

Untuk itu dalam simulasi ini kami membatasi besarnya frekuensi input pada mana mobil melewati profil jalan sinusoidal ini mulai dari $1 \mathrm{~Hz}$ sampai dengan batas nyaman menurut Jane way, walaupun kondisi reilnya masih berada di bawah harga frekuensi yang diinputkan. Hasil simulasi harmonic analisys menunjukan bahwa amplitudo dan besarnya depleksi yang terjadi masih berada dalam ambang batas keamanan dan kenyamanan penumpang atau

Tabel 1. Hasil Analisis Pegas Menggunakan Software Ansys 6.0

\begin{tabular}{lcccc}
\hline & Tegangan Maksimum (Pa) & Tegangan Minimum (Pa) & Defleksi Maksimum (m) & Defleksi Minimum (m) \\
\hline Pegas 1 & $0,151.10^{9}$ & 2095 & $0,344.10^{-3}$ & 0 \\
Pegas 2 & $0,7.10^{8}$ & $0,778.10^{7}$ & $0,345.10^{-3}$ & 0 \\
Pegas 3 & $0,545.10^{8}$ & 783047 & $0,346.10^{-3}$ & 0 \\
Pegas 4 & $0,746.10^{8}$ & 934541 & $0,347.10^{-3}$ & 0 \\
Pegas 5 & $0,74.10^{8}$ & $0,397.10^{7}$ & $0,349.10^{-3}$ & 0 \\
Pegas 6 & $0,731.10^{8}$ & $0,565.10^{7}$ & $0,351.10^{-3}$ & 0 \\
Pegas 7 & $0,703.10^{8}$ & $0,573.10^{7}$ & $0,353.10^{-3}$ & 0 \\
Pegas 8 & $0,619.10^{8}$ & $0,455.10^{7}$ & $0,355.10^{-3}$ & 0 \\
Pegas 9 & $0,62.10^{8}$ & $0,432.10^{7}$ & $0,357.10^{-3}$ & 0 \\
\hline
\end{tabular}


manusia. yang terjadi. Demikian juga hasil simulasi dengan harmonik analisys ini menunjukan bahwa harga tegangan maksimum yang terjadi pada tiap lempengan pegas masih berada dibawah harga kekuatan ijin bahan. Dengan demikian baik secara statis maupun dinamis pemakaian pegas daun sebagai suspensi kendaraan roda empat ini masih memenuhi syarat.

Melihat dari jumlah lempengan pada konstruksi pegas daun yang dianalisa maupun yang dipakai pada umumnya bahwa jumlah lempengan akan berpengaruh pada karakteristik suspensi. Hal ini memang benar adanya, mengingat walaupun dengan lima lempengan ternyata pada lempengan pegas tertentu yang justru memerima atau terjadi tegangan maksimum yang cukup besar disbanding pada lempengan yang lain. Karena itu dengan menganalisa atau memperhatikan hasil simulasi konstruksi susunan pegas dengan lima lempengan bisa dianalogkan bahwa untuk kondisi kendaraaan yang sama serta dengan konstrain yang sama pula bisa dipastikan akan memberikan efek yang berbeda atau bahkan jauh berbeda jika jumlah susunan atau lempengan pegas dikurangi. Hal ini bisa dijelaskan dengan besarnya momen maksimum yang terjadi pada posisi tengah.

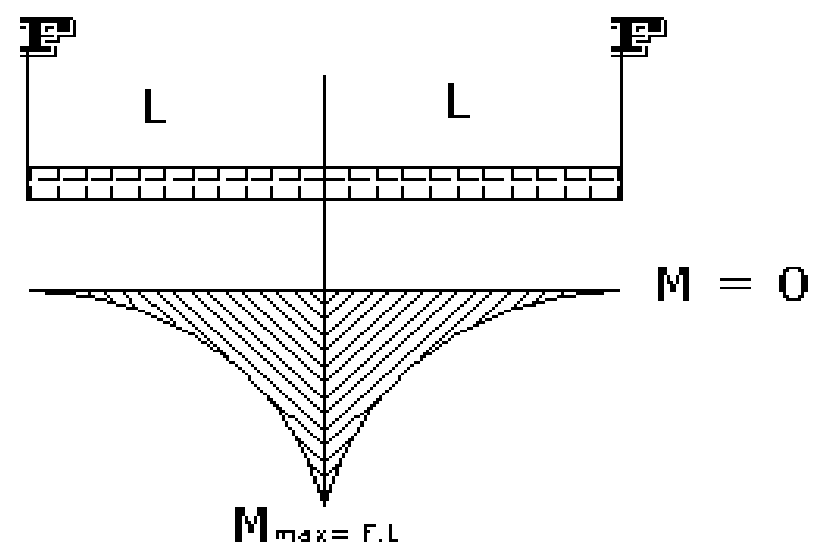

Gambar 3. Bidang Momen pada Model Pegas yang Dijepit di Tengah

Dengan demikian, semakin banyak susunan mestinya akan sanggup menahan atau memberika momen tahanan yang lebih kuat pula. Tetapi karena konstrin ruang dan beaya produksi yang ada, maka dengan sembilan lempengan ini kiranya kondisinya sudah menguntungkan baik ditinjau dari segi keamanan maupun biaya produksinya.

Ditinjau dari besarnya ampiltudo dan besarnya frekuensi eksitasi yang terjadi pada system suspensi diatas yamg besarnya 1-6 $\mathrm{Hz}$, maka menurut standart kenyamanan dari Jane way besarnya amplitudo haruslah berada pada range $0 \mathrm{~s} / \mathrm{d} 50 \mathrm{~mm}$.
Sehingga dari hasil simulasi harmonik diatas bisa dikatakan bahwa pemakaian suspensi pegas daun pada poros belakang kendaraan roda empat ini masih memebrikan kenyamanan bagi penumpangnya.

\section{Standar Kenyamanan menurut Janeway}

Kenyamanan penumpang pada kendaraan darat telah dirumuskan oleh Jane way yang mendasarkan kenyaman penumpang ini pada hubungan laju kecepatan, percepatan terhadap amplitude dan frekuensi getar yang terjadi. Pada umumnya tingkat kenyamanan tersebut didasarkan pada tiga level frekuensi yaitu masing-masing pada frekuensi level pertama pada 1-6 Hz, kedua pd frekuensi $6-20 \mathrm{~Hz}$ dan level ketiga pada frekuensi $20-60 \mathrm{~Hz}$. Untuk level frekuensi $1-6 \mathrm{~Hz}$ harga maksimum dari Jerk atau besarnya percepatan getaran persatuan waktu tidak boleh melebihi 12,6 m/dt ${ }^{3}$ atau sebesar $496 \mathrm{in} / \mathrm{detik}^{3}$. Kalau getaran system dianggap atau dimodelkan sebagai getaran harmonik atau mengikuti fungsi sinusoidal: $\mathrm{x}=\mathrm{A}$ sin wt, maka harga jerk adalah:

$$
\frac{d^{3} x}{d t^{3}}=A \omega^{3} \cos \omega t
$$

Harga jerk akan maksimum jika harga $\cos \omega t$ $=1$, Jerk maks. $=A \omega^{3}$. Analog untuk percepatan dan kecepatan maksimum yang diturunkan dari persamaaan perpindahan $x=A \sin \omega t$ di atas akan diperoleh:

- Untuk percepatan maksimum $=$

$$
\frac{d^{2} x}{d^{2} t}=-A \omega \sin \omega t=A \omega^{2}
$$

- Untuk kecepatan maksimum =

$$
\frac{\mathrm{dx}}{\mathrm{dt}}=\mathrm{A} \omega \cos \omega \mathrm{t}=\mathrm{A} \omega
$$

Yang mana untuk level frekuensi dari 1-6 Hz, besarnya amplitudo maksimum adalah:

$$
\mathrm{A}_{1}=\frac{12,6}{\omega^{3}} \frac{\mathrm{m} / \mathrm{dt}^{3}}{\left(\mathrm{rad} / \mathrm{dt}^{3}\right)}=\frac{12,6}{(2.3,14)^{3}}=0,0508 \mathrm{~m}=2 \text { in.; }
$$

$(1 \mathrm{~Hz}=2 \Pi \mathrm{rad} / \mathrm{dt})$

Untuk level 2 mulai frekuensi 6-20 Hz besarnya percepatan maksimum yang diijinkan pada batas nyaman adalah: $0,33 \mathrm{~m} / \mathrm{dt}^{2}$ maka amplitudo 
maksimum yang diturunkan dari hubungan ini adalah:

$$
\mathrm{A}_{2}=\frac{0,33}{\omega^{2}} \frac{\mathrm{m} / \mathrm{dt}^{2}}{\mathrm{rad} / \mathrm{dt}^{2}}=\frac{0,33}{(2.3,14)^{2}}=.0,008 . . \mathrm{m}
$$

Untuk level frekuensi $20-60 \mathrm{~Hz}$, besarnya amplitudo maksimum yang diijinkan didasarkan pada kecepatan maksimum yang diijinkan yaitu sebesar $2,7 \mathrm{~mm} / \mathrm{dt}$ atau sekitar $0,105 \mathrm{in} / \mathrm{dt}$, maka besar amplitudo maksimum yang diijinkan adalah:

$$
\mathrm{A}_{3}=\frac{2,7}{\omega} \frac{\mathrm{m} / \mathrm{dt}}{\mathrm{rad} / \mathrm{dt}}=\frac{2,7}{6,28} \mathrm{~mm}=0,43 \mathrm{~mm}
$$

Ditinjau dari besarnya ampiltudo dan besarnya frekuensi eksitasi yang terjadi pada system suspensi diatas yamg besarnya $1-6 \mathrm{~Hz}$, maka menurut standart kenyamanan dari Jane way besarnya amplitudo haruslah berada pada range $0 \mathrm{~s} / \mathrm{d} 50 \mathrm{~mm}$. Sehingga dari hasil simulasi harmonik diatas bisa dikatakan bahwa pemakaian suspensi pegas daun pada poros belakang kendaraan roda empat ini masih memberikan kenyamanan bagi penumpangnya.

\section{SIMPULAN}

Dari penelitian, didapatkan bahwa harga frekuensi natural dari hasil modal analisis adalah untuk gerakan menyamping $115 . \mathrm{Hz}$, untuk gerakan keatas dan ke bawah $149 \mathrm{~Hz}$, untuk gerakan ke depan dan ke belakang $283 \mathrm{~Hz}$, dan gerakan satu posisi $189 \mathrm{~Hz}$. Dengan analisa harmonik mulai frekuensi 1-6 $\mathrm{Hz}$ diperoleh besarnya lendutan maupun tegangan maksimum masih dibawah harga yang diijinkan untuk material pegas yang dipakai.

\section{DAFTAR PUSTAKA}

Fu, Cebon, 2002. Analysis of truck suspension data base, International Journal of Vehicle Design Heavy Vehicle System. National Taiwan University.

Khurmi, G., 1982. Text Book of Machine Design. New Delhi.

Miftahurrozi, D., 2003. Optimasi Kelengkungan Lempengan Pegas Daun. UMM.

Nanang, T.S., 2004. Distribusi tegangan pegas Daun pada Dump Truck, UMM.

Norman, E.D., 2002. Mechanical Behavior of Material International Student Edition.

Shankar, V., 2006. Mono Composite Leaf Spring for Light Weight Vehicle. Journal material Science.

Tomy, Daryono, 2005. Analisa Kekuatan Pegas Daun kendaraan Kijang, Technical Report, Graduate Student, UMM.

Wijayanto, B. dan Daryono, 2002. Optimasi Gelagar Technical Report, Graduate student. UMM. 